\title{
Buckling Analysis of Multi-Storey Steel Building with and without Bracing under different Soil Conditions
}

\author{
Vidyasagar. $\mathrm{P}^{[1]}$ Kiran. K. K ${ }^{[2]}$ \\ ${ }^{[1]} P G$ Student, Department of Civil Engineering, SJBIT, Bengaluru \\ ${ }^{[2]}$ Assistant Professor, Department of Civil Engineering, SJBIT, Bengaluru
}

\begin{abstract}
The major concern in the design of multistoriedtall steel building is to have good buckling load resisting system along with gravity load system because it also governs the design. This paper is presented to show the effect of different types of bracing systems in multistoried tall steel buildings on buckling behavior of the structure under different soil condition. For this purpose, multi storey steel building models without and with different bracing systems such as Diagonal, $X$ bracing, inverted ' $V$ ' bracing and $K$ bracing system under different soil condition. $A$ commercial software package ETABS is used for the analysis of steel buildings and different parameters are compared with buckling factors. The property of the section is used as per IS 800:2007 which incorporates Limit State Design philosophy.
\end{abstract}

Key words: Buckling Factor, X brace, K brace, Inverted V brace, Tall buildings, Slender Column.

\section{Introduction}

Buckling analysis is the technique used to determine buckling load or critical load at which structure become unstable and buckled to mode shape and the shape associate with the structure is bucked response.In other words, once critical load is reached, the slender component draws aside instead of talking up additional load. This failure can be analysed using a technique known as buckling analysis. The goal of this analysis is to determine buckling load factor and critical buckling load. And buckling load is calculated by using formula given below.

Buckling Load = Applied Load $\mathrm{x}$ Buckling Factor

Steel has some important physical properties like a high strength per unit load \& ductility when contrasted with RCC. Because of more yield and ultimate strength member part sizes compressing the Slender sections because of slenderness of the section buckling may induce in the member. bracing is required to restrain horizontal buckling of the structure. To study buckle behavior of the member many study has been introduced. A short review is given here, BehroozFarshi and Farshad Kooshesh (2009), concentrated on buckle analysis of structural 2D Steel frames with inelastic impacts as indicated by euro codes. With a specific end goal to numerical Illustrate proposed strategy example cases are working out. at last, the results of given in curves \& tables for examination with more compelling option technique presently utilized book line capacity of the steelframed buildings. K. P. Shadiya and Anusha. R (2015), Focused on buckle restrained brace frames (BRBF's) and consider the reaction of different bracing arrangement on the behavior of buckle restrained braced frames (BRBF's). 5 Story 3 Bay braced frames with 3 distinct patterns are modelled using FEM programming software called as ANSYS. the principle variable in this review is types of the bracing \& the area of the bracing. The impact of the bracing arrangement on seismic action of buckle restrained braces are also taken in account. The top combination of bracing arrangement and area of location along with definite way with the height of the storey as far as seismic reaction are finally recommended. In this research " $\mathrm{X}$ " bracing configuration or ross bracing configuration have got very little stress \& small deformation under the present load condition and it is most effective \& best bracing system to oppose under the intense load condition.Y. Huang and X.- F. Li (2013), In the paper analytical approach is done to tackle buckling insecurity of column segment with different cross area including pined pinned sections, clamed sections and cantilever columns. And the results, the outcomes are contrasted with numerical approach. At last, they inferred that analytical type of approach gives exact outcome when contrasted with numerical technique and the critical load of the sections is effectively dictated by presence state of non- trivial solution.

\section{Objective Of This Paper}

The main aim of the current study is to carry out buckling analysis of steel building without and with differentbracing system by utilizing ETABSsoftware and the preliminary destinations of the study are as per the following. 
- To carry buckling analysis on 5, 10, 15 and 20 storey steel buildings and to find out the buckling factors.

- To study the effect of slenderness of column on global bucking behaviour of the building.

- To compare the buckling factor of steel framed building without and with different sort of bracing.

- To compare\& quantify the buckling loads for steel framed building with different types of bracing.

- To study the effect of the soil structure interaction on the bucklingbehaviour of thestructure by modelling the foundation using linear springs.

- $\quad$ To study the influenceof stiffness of bracing on the buckling factors.

\section{Methodology}

The current analysis is an analytical study using ETABS by considering steel framed building of 05 , 10, 15 and 20 storey height. Buckling factors shall be find out by performing a finite element buckling analysis in ETABS and all loading and design shall as per as Indian codes. Comparison in terms of buckling factors. The column c/s shall be varied to find out the effect of slenderness ratio of columns on buckle load on components. Different bracing (K Bracing, Inverted ' $\mathrm{V}$ ' Bracing, $\mathrm{X}$ Bracing and single diagonal Bracing) shall be adopted to compare the increase in buckling factor by the adoption of bracing. Foundation flexibility shall be modeled using linear springs as per Gezetas (1991) equation.

\begin{tabular}{|c|c|}
\hline Stiffness parameter & Rigid plate stiffness at surface, $K_{i o}$ \\
\hline Vertical Translation, $\mathrm{K}_{\mathrm{zo}},(\mathrm{kN} / \mathrm{m})$ & $\frac{G L}{1-\mu}\left[0.73+1.54\left(\frac{B}{L}\right)^{0.75}\right]$ \\
\hline $\begin{array}{l}\text { Horizontal Translation, } \mathrm{K}_{\mathrm{yo}},(\mathrm{kN} / \mathrm{m}) \\
\text { (towards long side) }\end{array}$ & $\frac{G L}{2-\mu}\left[2+2.5\left(\frac{B}{L}\right)^{0.85}\right]$ \\
\hline $\begin{array}{l}\text { Horizontal Translation, } \mathrm{K}_{\mathrm{xo}},(\mathrm{kN} / \mathrm{m}) \\
\text { (towards short side) }\end{array}$ & $\frac{G L}{2-\mu}\left[2+2.5\left(\frac{B}{L}\right)^{0.85}\right]-\frac{G L}{0.75-\mu}\left[0.1\left(1-\frac{B}{L}\right)\right]$ \\
\hline $\begin{array}{c}\text { Rotation, } \mathrm{K}_{\theta \mathrm{xo}},(\mathrm{kN} / \mathrm{rad}) \\
(\text { about } \mathrm{x} \text { axis })\end{array}$ & $\frac{G}{1-\mu} I_{X}^{0.75}\left(\frac{L}{B}\right)^{0.25}\left(2.4+0.5 \frac{B}{L}\right)$ \\
\hline $\begin{array}{l}\text { Rotation, } \mathrm{K}_{\theta \mathrm{yo}},(\mathrm{kN} / \mathrm{rad}) \\
\text { (about y axis) }\end{array}$ & $\frac{G}{1-\mu} I_{Y}^{0.75}\left[3\left(\frac{L}{B}\right)^{0.15}\right]$ \\
\hline
\end{tabular}

Table 1: Gezetas (1991) equations

Here,

$\mathrm{E}=$ Young's modulus of elasticity of soil

$\mu=$ Poisson's ratio of soil

$\mathrm{G}=$ Shear modulus of elasticity of soil $=\frac{E}{2(1+0)}$

$\mathrm{L}=$ Length of the footing

$\mathrm{B}=$ Width of the footing

$I_{x}, I_{y}=$ Moments of inertia of the footing with respect to longitudinal and transverse directions respectively

Gezetas has provided a set of empirical equations for estimating various stiffness values of rectangular footings laying on ground surface. In the similar way, it has been taken for considering foundation flexibility. By using these Gezetas (1991) formula for various soil condition stiffness has been calculated and assigned to calculate the buckling factor by buckling analysis.

\section{Modelling And Analysis}

In the currentstudy, 4 structures ranging from 5 storeys to 20 storeys are taken. Fig. 2 shows the typical plan taken for the study.

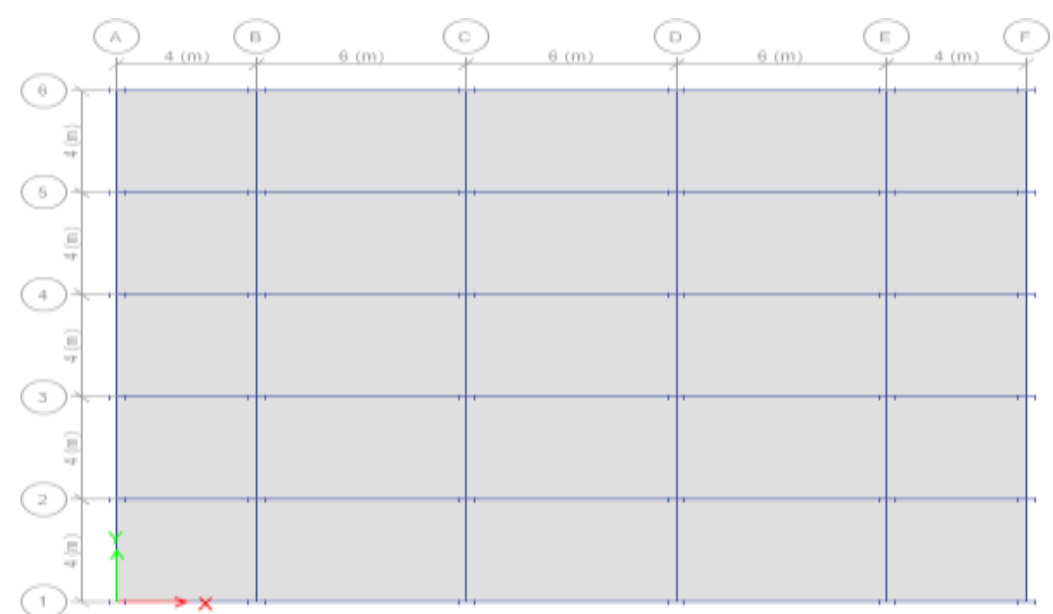

Fig 1: Typical plan of the building taken 


\begin{tabular}{|c|c|}
\hline PARAMETER & TYPE / VALUE \\
\hline Number of stories & $5,10,15$ and 20-storey \\
\hline Typical storey height & $3.5 \mathrm{~m}$ \\
\hline Type of building for use & Public building \\
\hline Beam size & ISMB 600 \\
\hline Column size & varies \\
\hline Thickness of slab & $0.150 \mathrm{~m}$ \\
\hline Live Load & $3 \mathrm{kN} / \mathrm{m} 2$ \\
\hline Floor finishes & $1.5 \mathrm{kN} / \mathrm{m} 2$ \\
\hline Wall load & $15.3 \mathrm{kN} / \mathrm{m} 2$ \\
\hline
\end{tabular}

Table 2. Building parameters taken for the modelling

\section{A. Models Geometry}

\begin{tabular}{|c|c|}
\hline No of bays in $\mathrm{X}$ direction & 5 \\
\hline Bay width in $\mathrm{X}$ direction & varies \\
\hline No of bays in Y direction & 5 \\
\hline Bay width in Y direction & $4 \mathrm{~m}$ \\
\hline
\end{tabular}

Table 3: Models Geometry

\section{B. Description of Steel Frame Models}

In currentstudy, the steel structural models have been taken. The model of the steel structure show has taken into 3 classes.

1) Model without any bracing

2) Model with different sort of bracing

3) Model with springs support at base

C. Models

The elevation of the building and 3Dview of the structures considered for the examination are displayed in the below figures.

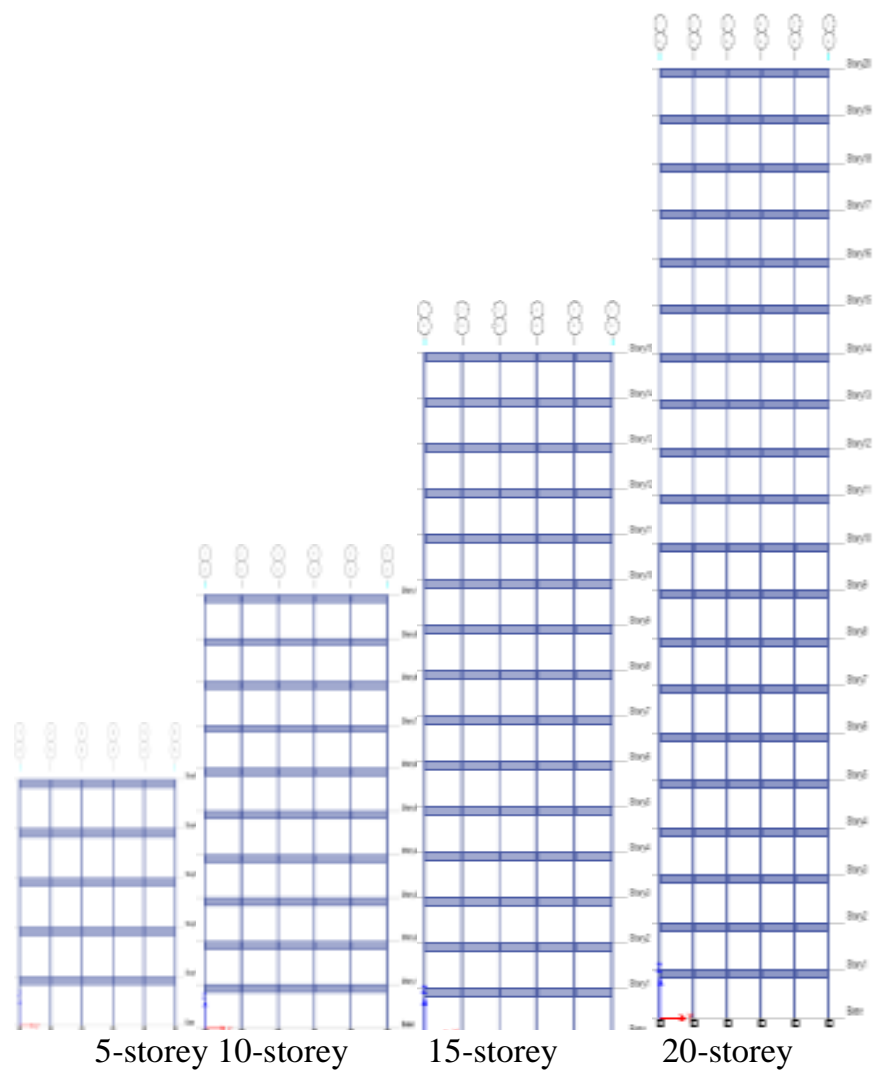

Fig 2: Elevations for the structures without bracing 


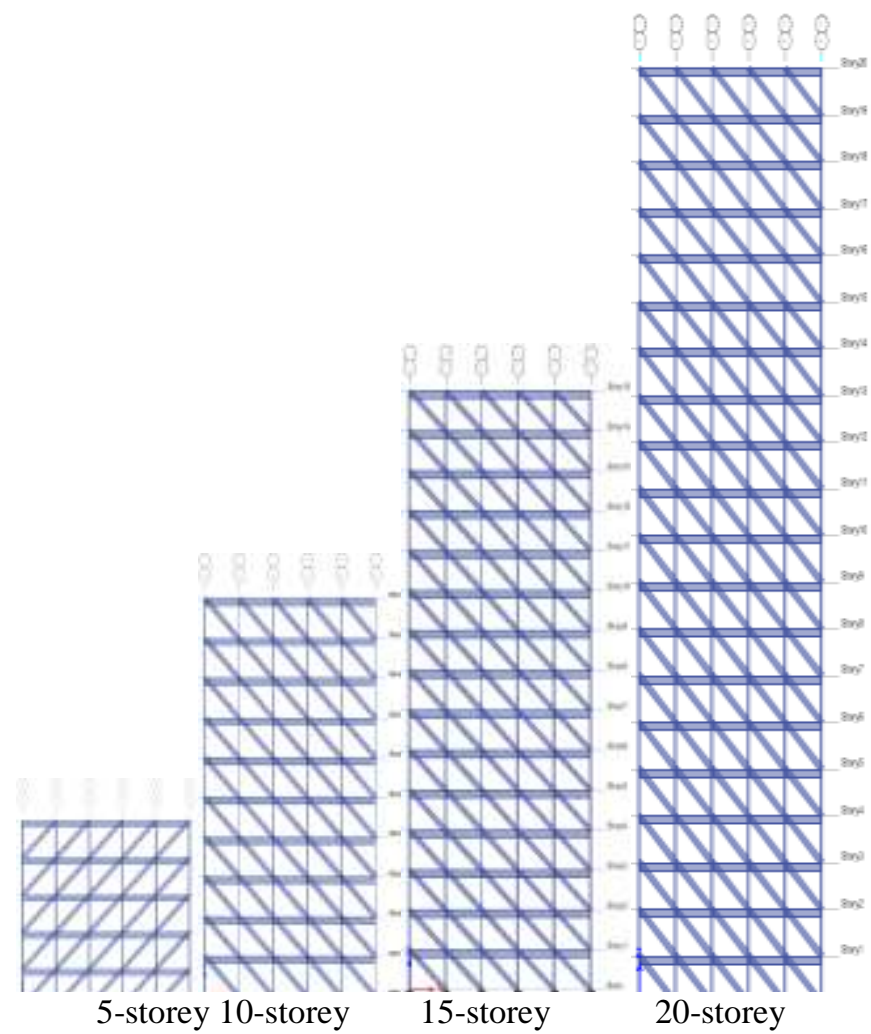

Fig 3: Elevations for the structures with Diagonal bracing

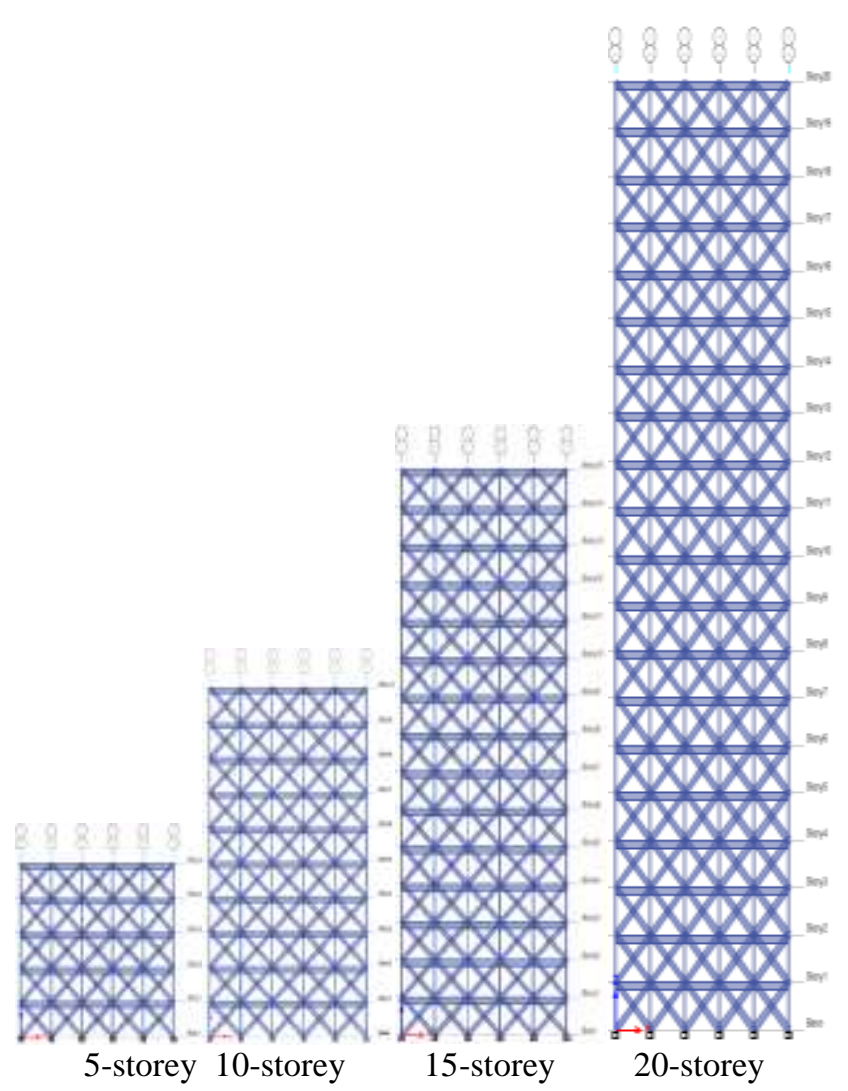

Fig 4: Elevations for the structures with " $\mathrm{X}$ " bracing 


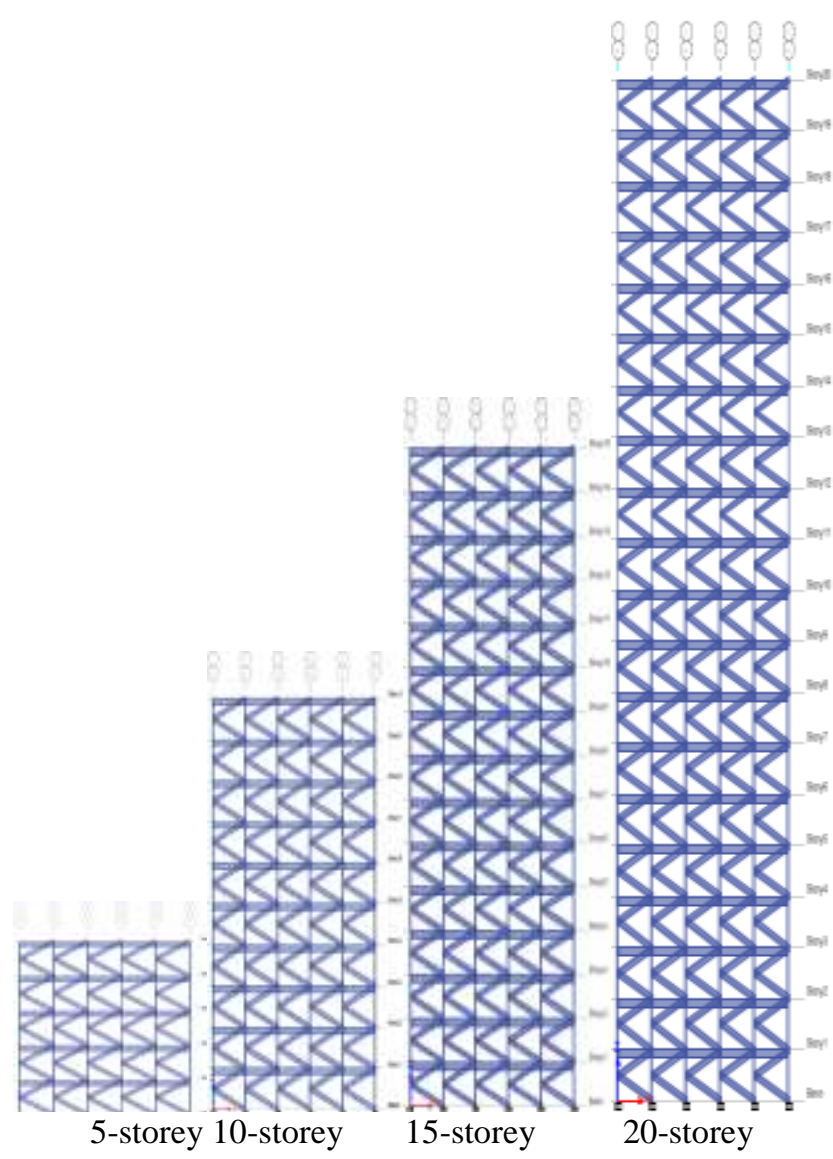

Fig 5: Elevations for the structures with "K" bracing

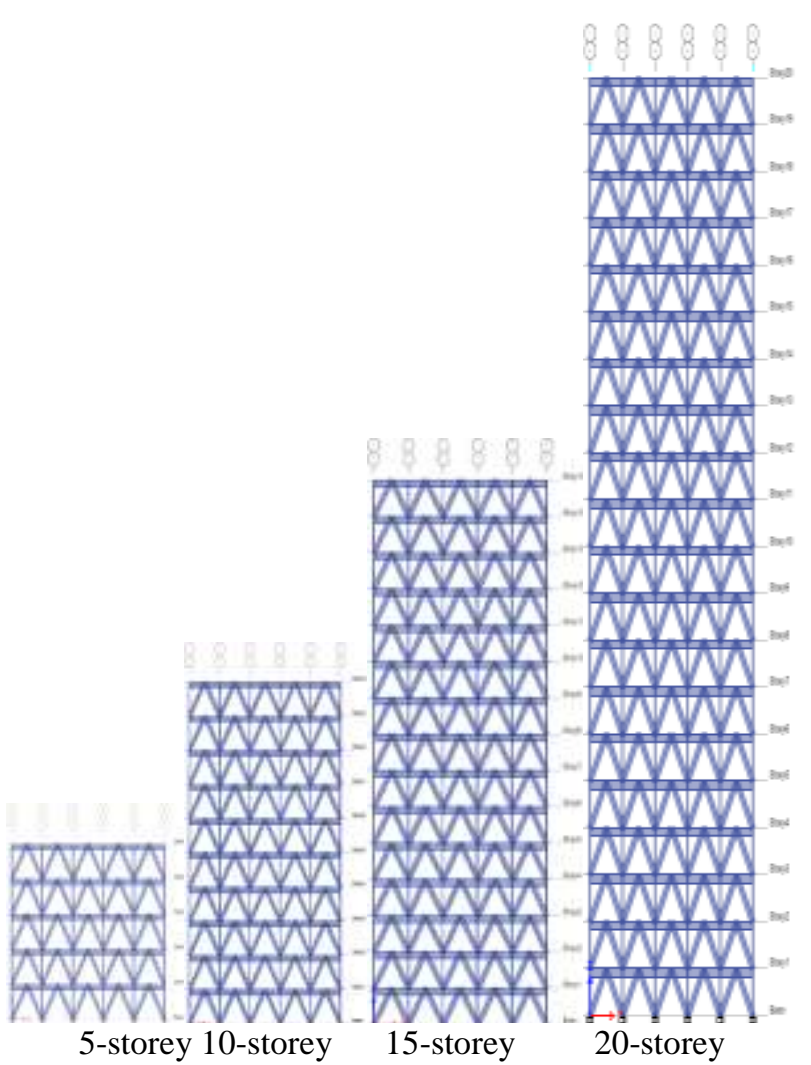

Fig 6: Elevations for the structures with inverted "V" bracing 


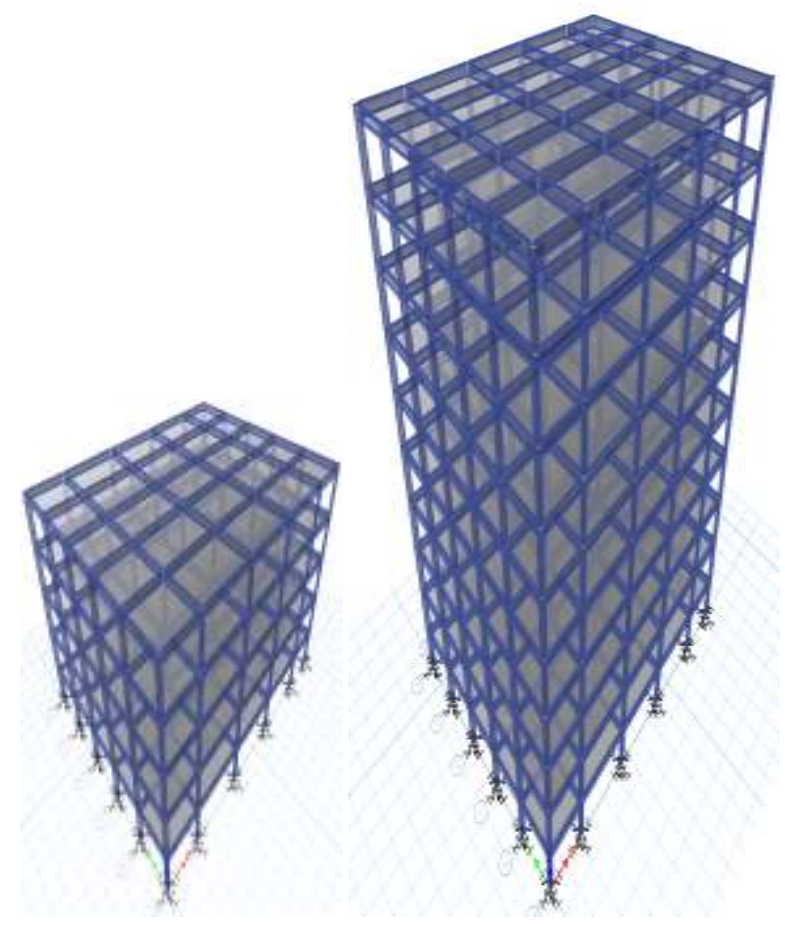

5-storey 10-storey

Fig 7:3D model with springs support at base
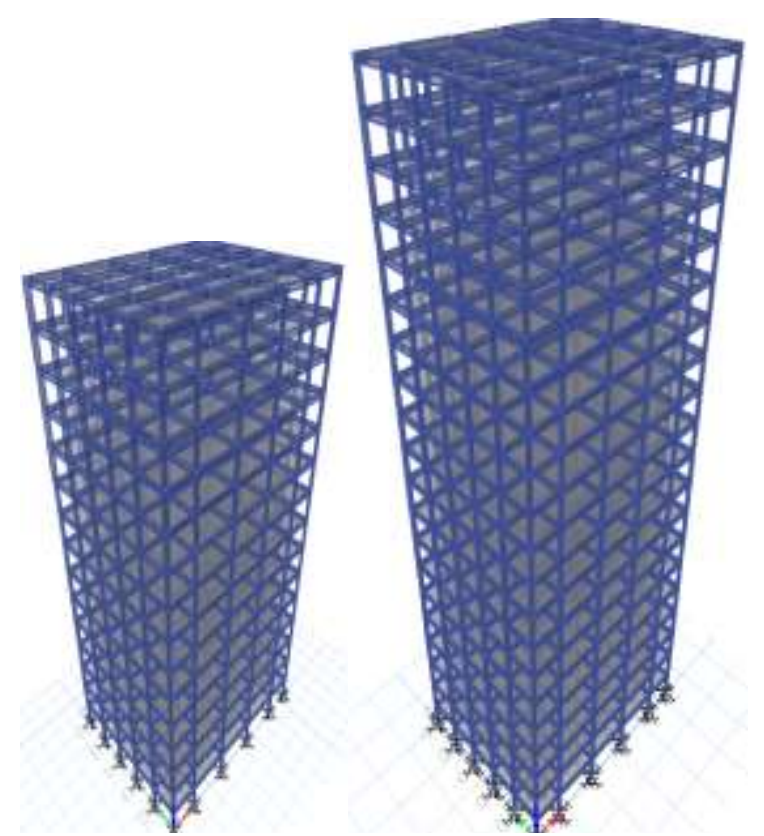

Fig 8:3D model of structure with springs support at base

\section{Results}

Case $1-5$ storey structure

1. Effect of slenderness of column on global bucking behaviour of the structure

\begin{tabular}{|c|c|c|c|}
\hline Section & $\mathbf{R m i n}(\mathbf{m m})$ & $\mathbf{k L / r} \mathbf{( m m})$ & Buckling factor \\
\hline ISMB 600 & 41.2 & 84.95 & 3.592 \\
\hline ISMB 550 & 37.3 & 93.83 & 2.501 \\
\hline ISMB 500 & 35.2 & 99.43 & 1.877 \\
\hline ISMB 450 & 30.1 & 116.2 & 1.094 \\
\hline ISMB 400 & 28.4 & 123.2 & 0.859 \\
\hline
\end{tabular}

Table 4: Details of 5 storey analysis 


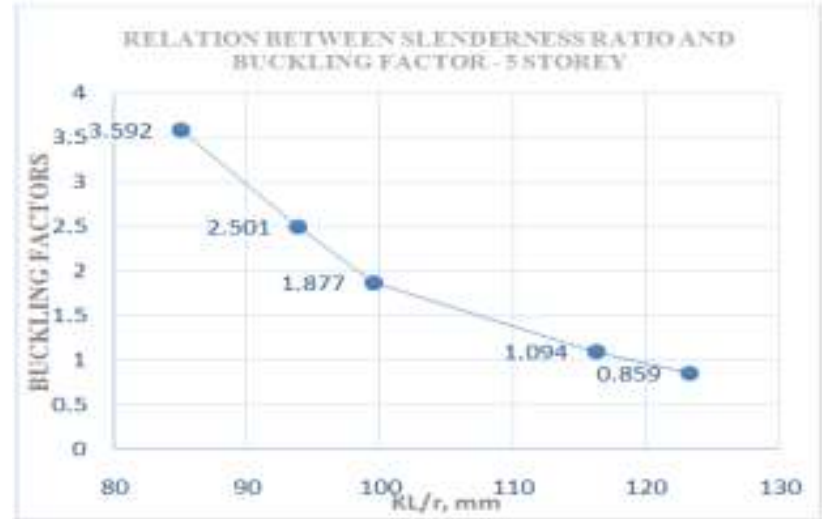

Fig 9:Relation between Slenderness ratio and Buckling factor

2. Variation of buckling factor with different types of bracing system

\begin{tabular}{|c|c|}
\hline Frame Type & Buckling factor \\
\hline Bare Frame & 3.592 \\
\hline Diagonal braced frame & 3.625 \\
\hline "X" Braced Frame & 8.868 \\
\hline "K" Braced Frame & 13.052 \\
\hline Inverted "V" Braced Frame & 16.935 \\
\hline
\end{tabular}

Table 5: Details of 5 storey analysis

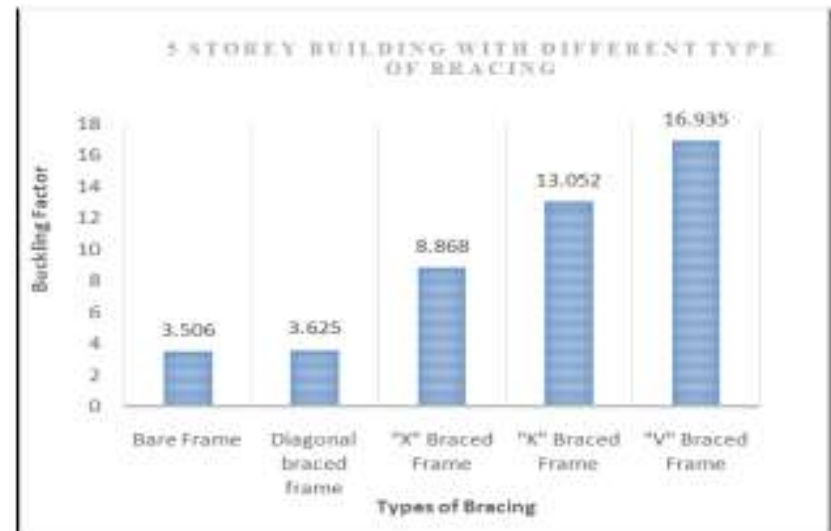

Fig 10:Variation of buckling factor with different types of bracing system

3. Effect of the soil structure interaction on the buckling behaviour of the structure

\begin{tabular}{|c|c|}
\hline Soil Type & Buckling factor \\
\hline Very Soft soil & 0.371 \\
\hline Medium sand & 0.819 \\
\hline Gravel & 1.079 \\
\hline Broken Stone & 1.088 \\
\hline Fixed support & 1.094 \\
\hline
\end{tabular}

Table 6: Details of 5 storey analysis

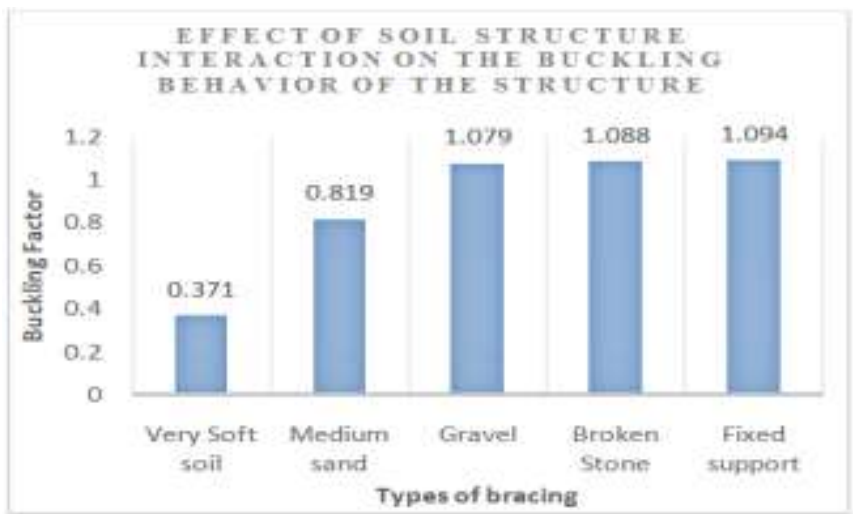

Fig 11:Variation of the soil structure interaction on the buckling behaviour of the structure. 
4. Influence of stiffness of bracing on the buckling factor.

\begin{tabular}{|c|c|}
\hline Section & Buckling factor \\
\hline ISMB 250 & 8.486 \\
\hline ISMB 300 & 10.783 \\
\hline ISMB 350 & 12.227 \\
\hline ISMB 400 & 13.667 \\
\hline ISMB 450 & 16.935 \\
\hline
\end{tabular}

Table 7: Details of 5 storey analysis

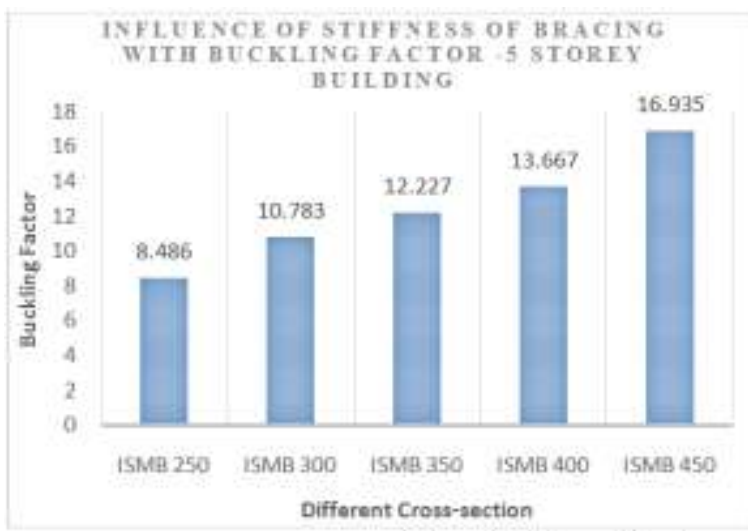

Fig 12: Variation of stiffness of bracing on the buckling factor

Case 2 - 10 storey structure

1. Effect of slenderness of column on global bucking behaviour of the structure

\begin{tabular}{|c|c|c|c|}
\hline Section & $\mathbf{R m i n}(\mathbf{m m})$ & $\mathbf{k L / r} \mathbf{( m m})$ & Buckling factor \\
\hline ISMB 600 & 53.5 & 65.42 & 3.135 \\
\hline ISMB 550 & 51.1 & 68.49 & 2.514 \\
\hline ISMB 500 & 49.6 & 70.56 & 2.020 \\
\hline ISMB 450 & 41.1 & 85.15 & 1.166 \\
\hline ISMB 400 & 40.6 & 86.61 & 0.951 \\
\hline
\end{tabular}

Table 8: Details of 10 storey analysis

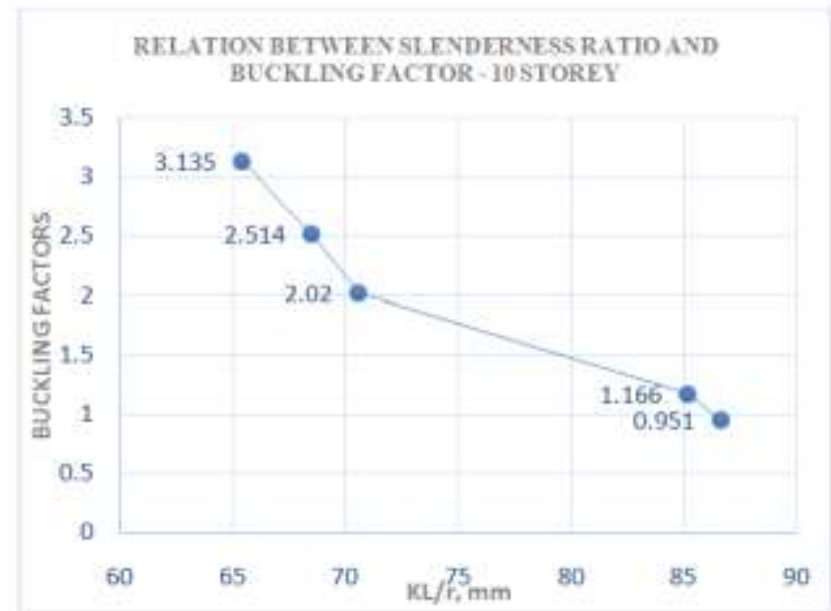

Fig 13: Relation between Slenderness ratio and Buckling factor

2. Variation of buckling factor with different types of bracing system

\begin{tabular}{|c|c|}
\hline Frame Type & Buckling factor \\
\hline Bare Frame & 1.166 \\
\hline Diagonal braced frame & 1.751 \\
\hline "X" Braced Frame & 5.419 \\
\hline "K" Braced Frame & 10.984 \\
\hline Inverted "V" Braced Frame & 13.646 \\
\hline
\end{tabular}

Table 9: Details of 10 storey analysis 


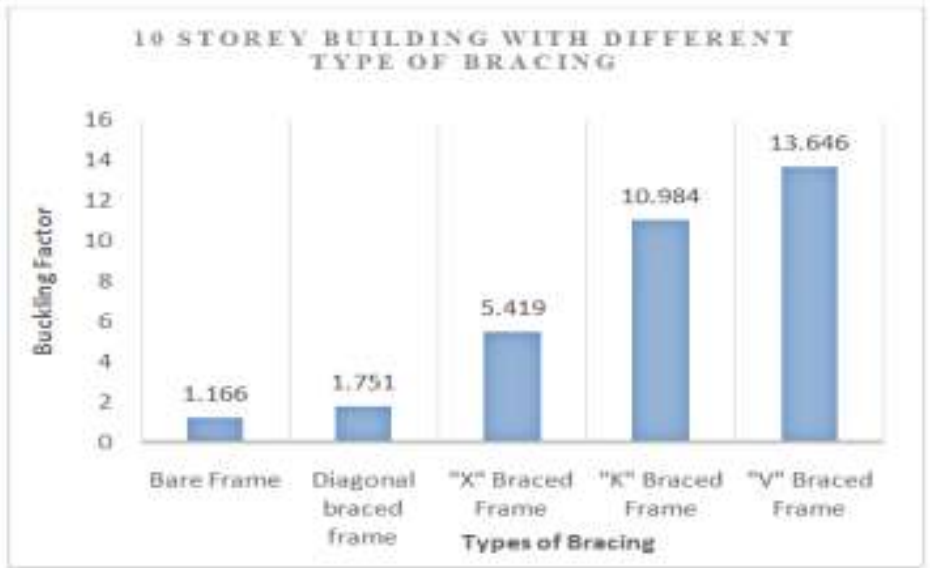

Fig 14:Variation of buckling factor with different types of bracing system

\section{Effect of the soil structure interaction on the buckling behaviour of the structure}

\begin{tabular}{|c|c|}
\hline Soil Type & Buckling factor \\
\hline Very Soft soil & 0.259 \\
\hline Medium sand & 0.696 \\
\hline Gravel & 1.133 \\
\hline Broken Stone & 1.155 \\
\hline Fixed support & 1.166 \\
\hline
\end{tabular}

Table 10: Details of 10 storey analysis

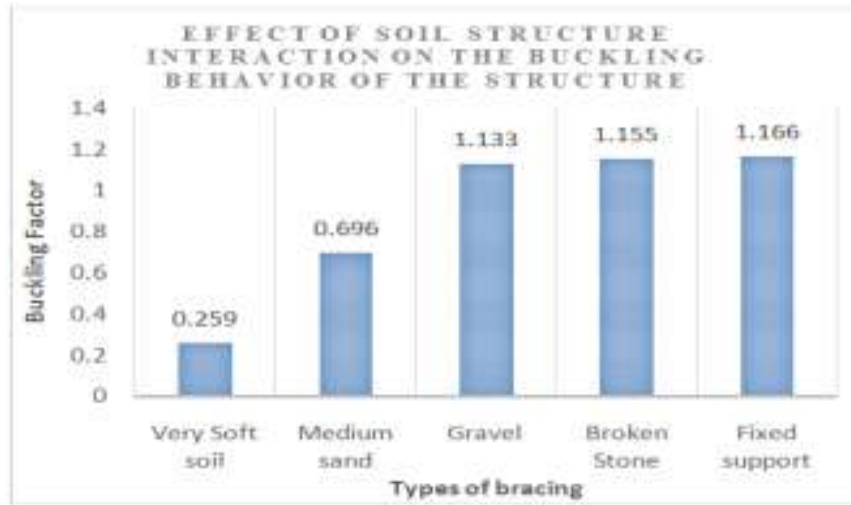

Fig 15: Variation of the soil structure interaction on the buckling behaviour of the structure

\section{Influence of stiffness of bracing on the buckling factor}

\begin{tabular}{|c|c|}
\hline Section & Buckling factor \\
\hline ISMB 250 & 6.649 \\
\hline ISMB 300 & 8.463 \\
\hline ISMB 350 & 9.551 \\
\hline ISMB 400 & 10.608 \\
\hline ISMB 450 & 13.646 \\
\hline
\end{tabular}

Table 11: Details of 10 storey analysis

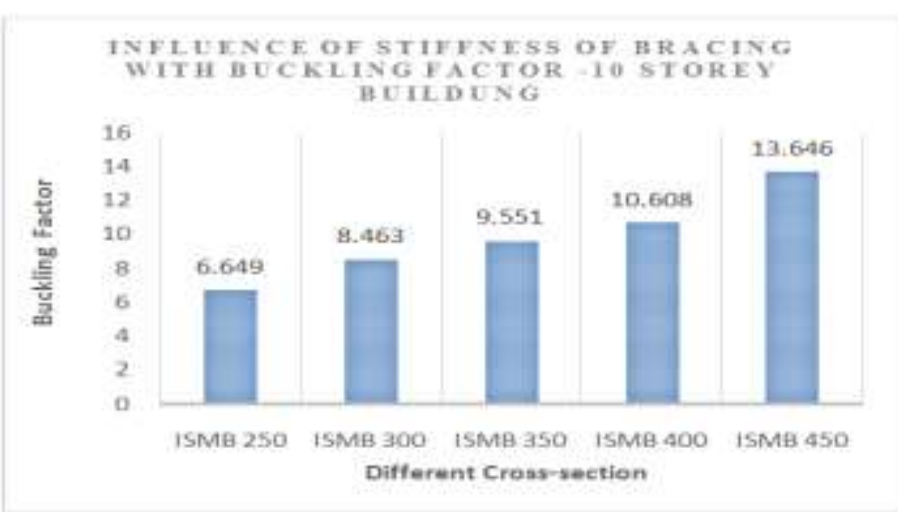

Fig 16:Variation of stiffness of bracing on the buckling factor 
Case 3 - 15 storey structure

1. Effect of slenderness of column on global bucking behaviour of the structure

\begin{tabular}{|c|c|c|c|}
\hline Section & $\mathbf{R m i n}(\mathbf{m m})$ & $\mathbf{~ k L / r} \mathbf{( m m})$ & Buckling factor \\
\hline ISMB 600 & 53.5 & 65.42 & 2.085 \\
\hline ISMB 550 & 51.1 & 68.49 & 1.673 \\
\hline ISMB 500 & 49.6 & 70.56 & 1.346 \\
\hline ISMB 450 & 41.1 & 85.15 & 0.777 \\
\hline ISMB 400 & 40.6 & 86.6 & 0.634 \\
\hline
\end{tabular}

Table 12: Details of 15 storey analysis

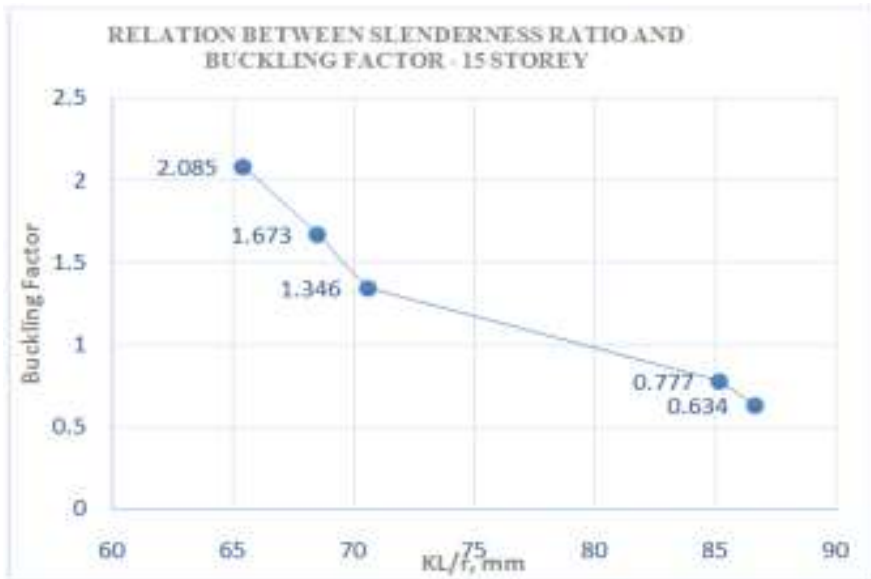

Fig 17:Relation between Slenderness ratio and Buckling factor

2. Variation of buckling factor with different types of bracing system

\begin{tabular}{|c|c|}
\hline Frame Type & Buckling factor \\
\hline Bare Frame & 0.777 \\
\hline Diagonal barced frame & 1.551 \\
\hline "X" Braced Frame & 3.457 \\
\hline "K" Braced Frame & 7.332 \\
\hline Inverted "V" Braced Frame & 9.266 \\
\hline
\end{tabular}

Table 13: Details of 15 storey analysis

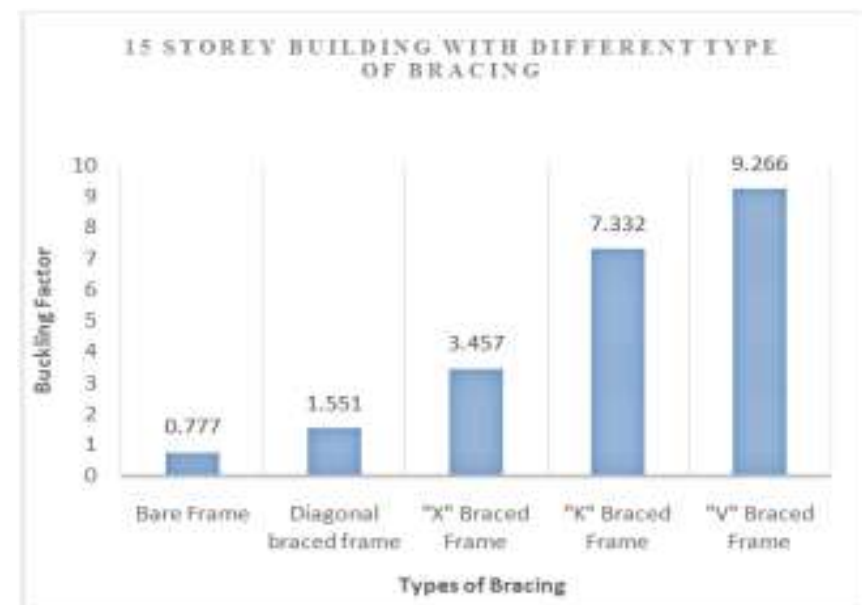

Fig 18: Variation of buckling factor with different types of bracing system

3. Effect of the soil structure interaction on the buckling behaviour of the structure

\begin{tabular}{|l|l|}
\hline Soil Type & Buckling factor \\
\hline Very Soft soil & 0.138 \\
\hline Medium sand & 0.461 \\
\hline Gravel & 0.724 \\
\hline Broken Stone & 0.768 \\
\hline Fixed support & 0.777 \\
\hline
\end{tabular}

Table 14: Details of 15 storey analysis 


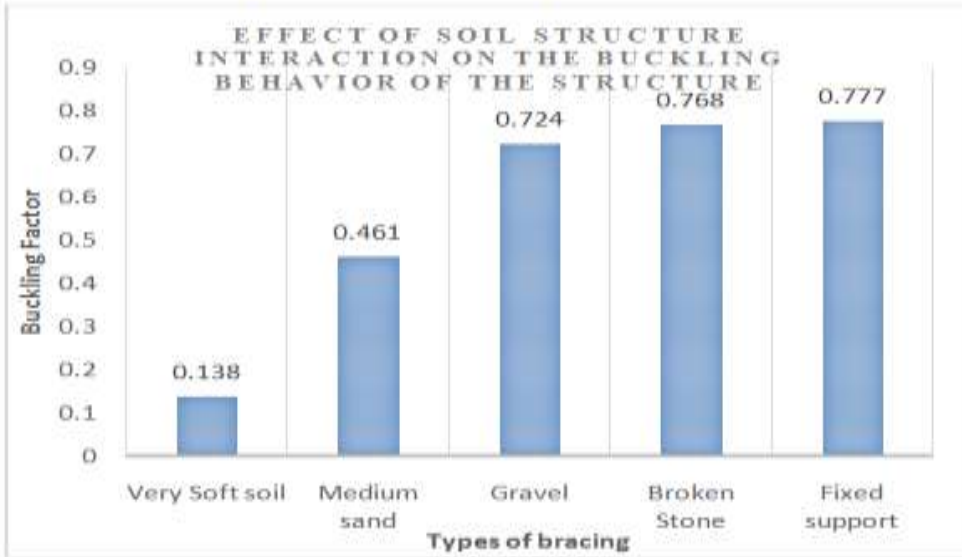

Fig 19:Variation of the soil structure interaction on the buckling behaviour of the structure

4. Influence of stiffness of bracing on the buckling factor

\begin{tabular}{|c|c|}
\hline Section & Buckling factor \\
\hline ISMB 250 & 4.565 \\
\hline ISMB 300 & 5.791 \\
\hline ISMB 350 & 6.514 \\
\hline ISMB 400 & 7.218 \\
\hline ISMB 450 & 9.266 \\
\hline
\end{tabular}

Table 15: Details of 15 storey analysis

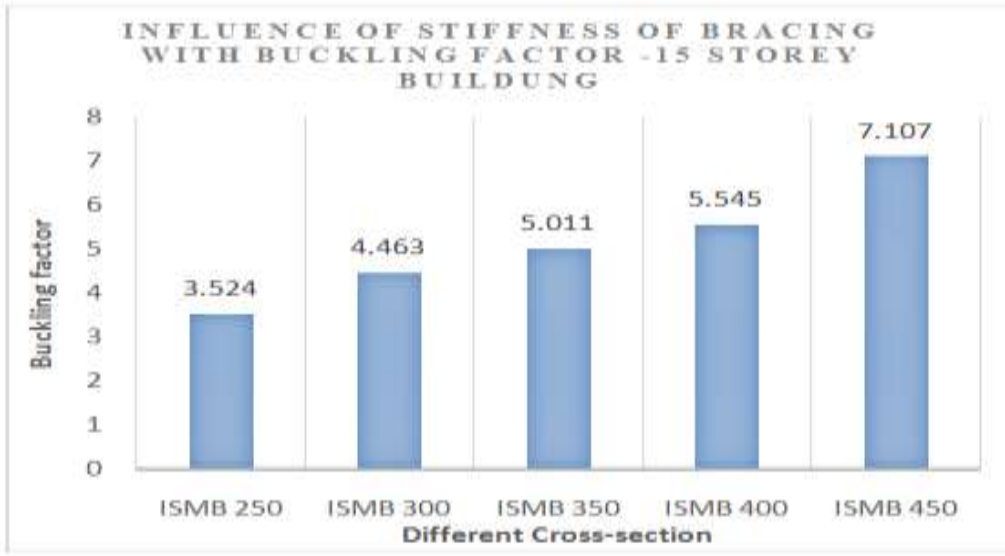

Fig 20: Variation of buckling factor with different types of bracing system

Case 4- 20 storey structure

1. Effect of slenderness of column on global bucking behaviour of the structure

\begin{tabular}{|c|c|c|c|}
\hline Section & Rmin $(\mathbf{m m})$ & $\mathbf{k l} / \mathbf{r}(\mathbf{m m})$ & Buckling factor \\
\hline ISWB 600 & 53.5 & 65.42 & 1.559 \\
\hline ISWB 550 & 51.1 & 68.49 & 1.253 \\
\hline ISWB 500 & 49.6 & 70.56 & 1.008 \\
\hline ISWB 450 & 41.1 & 85.15 & 0.583 \\
\hline ISWB 400 & 40.6 & 86.6 & 0.475 \\
\hline
\end{tabular}

Table 16: Details of 20 storey analysis

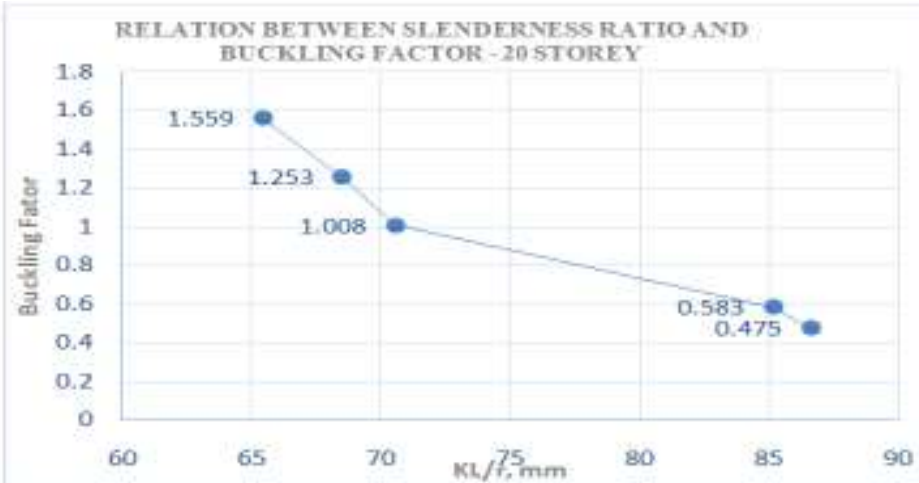

Fig 21: Relation between Slenderness ratio and Buckling factor 
2. Variation of buckling factor with different types of bracing system

\begin{tabular}{|c|l|}
\hline Frame Type & Buckling factor \\
\hline Bare Frame & 0.583 \\
\hline Diagonal barced frame & 1.153 \\
\hline "X" Braced Frame & 2.526 \\
\hline "K" Braced Frame & 5.484 \\
\hline Inverted "V" Braced Frame & 7.107 \\
\hline
\end{tabular}

Table 17: Details of 20 storey analysis

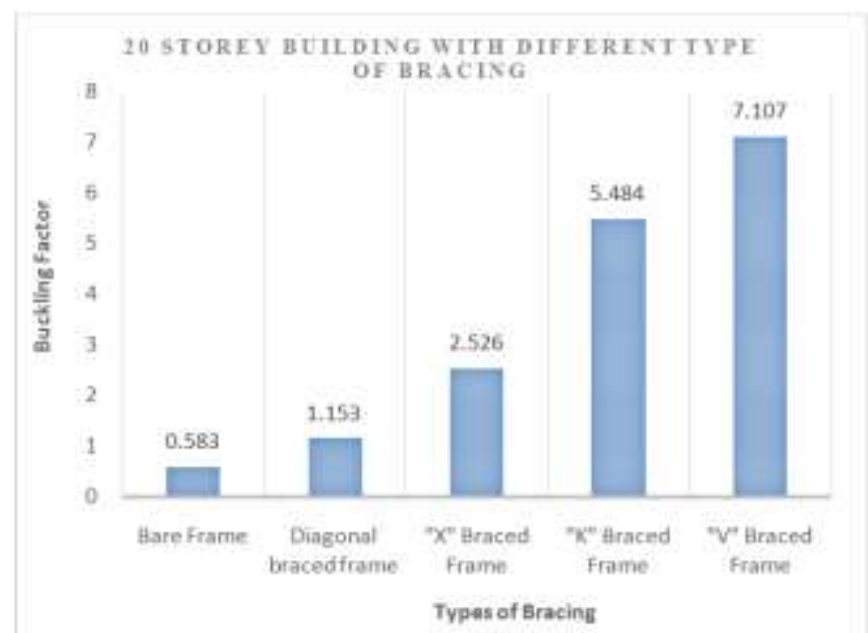

Fig 22:Variation of buckling factor with different types of bracing system

3. Effect of the soil structure interaction on the buckling behaviour of the structure

\begin{tabular}{|c|c|}
\hline Soil Type & Buckling factor \\
\hline Very Soft soil & 0.092 \\
\hline Medium sand & 0.344 \\
\hline Gravel & 0.501 \\
\hline Broken Stone & 0.577 \\
\hline Fixed support & 0.583 \\
\hline
\end{tabular}

Table 18: Details of 20 storey analysis

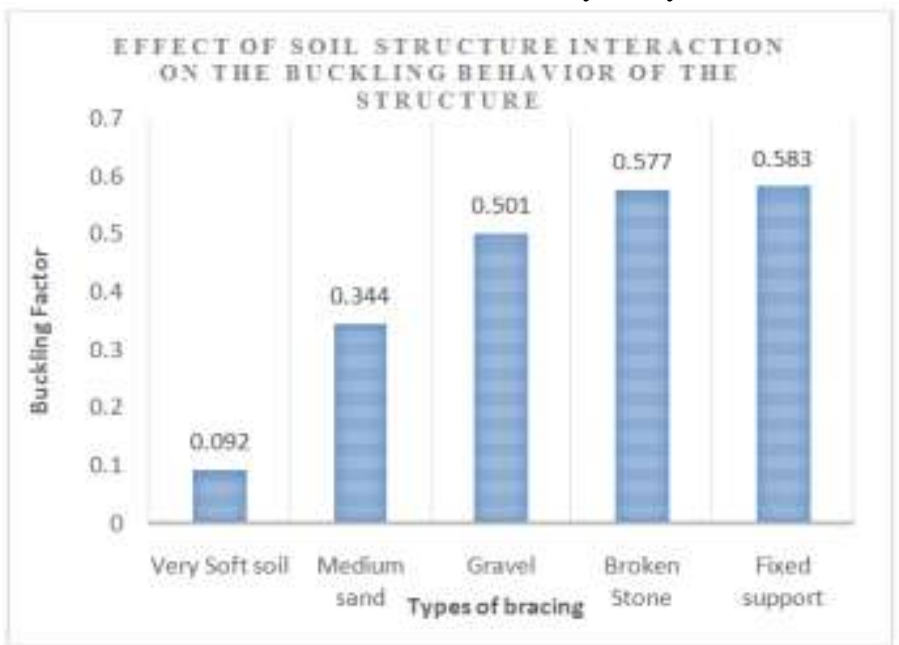

Fig 23: Variation of the soil structure interaction on the buckling behaviour of the structure

4. Influence of stiffness of bracing on the buckling factor

\begin{tabular}{|l|l|}
\hline Section & Buckling factor \\
\hline ISMB 250 & 3.524 \\
\hline ISMB 300 & 4.463 \\
\hline ISMB 350 & 5.011 \\
\hline ISMB 400 & 5.545 \\
\hline ISMB 450 & 7.107 \\
\hline
\end{tabular}

Table 19: Details of 20 storey analysis 


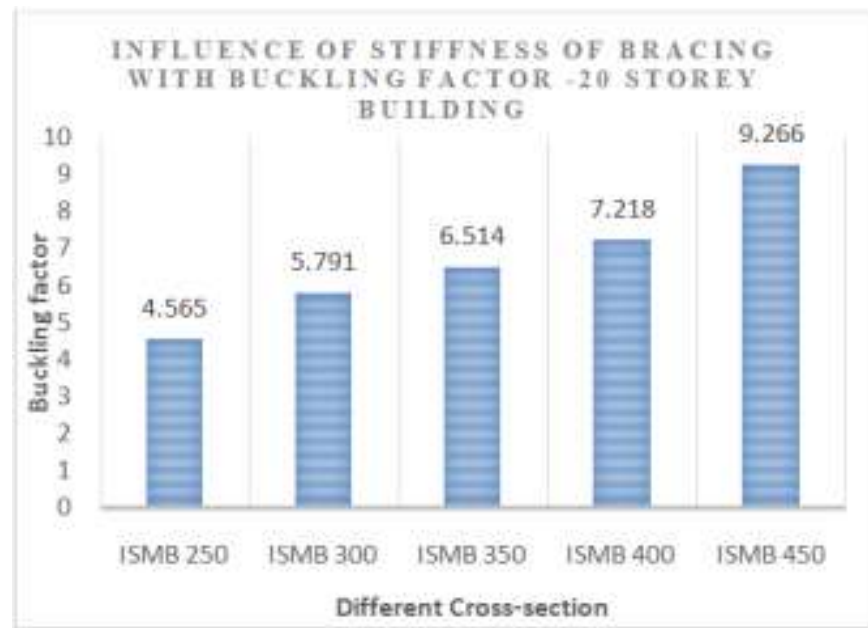

Fig 24:Variation of buckling factor with different types of bracing system

\section{Discussion}

Fig 9, Fig13, Fig 17and Fig 21 shows the effect of slenderness ratio of column on global bucking behaviour of the structure. And the Table 4, Table 8, Table 12 and Table 16 shows results in 5, 10, 15 and 20 storey respectively. From the result, it is noted that buckling factor will decrease as the slenderness of column increases.Table 5, 9, 13 and 17 shows the result of influence buckling factor with different types of bracing system in 5, 10, 15 and 20 storey buildings. From the result, it has been observed that the bare frame has less buckling load carrying capacity as compared to braced frame. And inverted "V" braced frames show high buckling load carrying capacity.Table 6, 10, 14 and 18 shows the results of effect of the soil structure interaction on the buckling behaviour of the structure in 5, 10, 15 and 20 storey building respectively. From the results, it is clear that buckling load carrying capacity is less in soft soil when we compared to hard rock and its almost equal to fixed support.Table 7,11, 15 and 19 show the results of influence of stiffness of bracing with buckling factor in 5, 10, 15 and 20 storey building respectively. Results shows as the stiffness bracing system increases the buckling factor also increases i.e. for cross section of bracing ISMB 400 the buckling factor is 7.107 and for the cross section ISMB 250 the buckling factor is 3.524 in 20 storey building.

\section{VII.Conclusion}

After the analysis of the structure with different types of bracing system it has been concluded that the buckling factor of the structure will increase after the application of bracing system when compared to the bare frame structure. The maximum buckling factor is obtained in case of Inverted' $\mathrm{V}$ ' Bracing model system in all 5, 10, 15 and 20 story building. when compared to other model of diagonal, $\mathrm{K}$ and $\mathrm{X}$ bracing system i.e. The performance of the Inverted ' $\mathrm{V}$ ' bracing Framework is superior to the remaining determined Bracing System. The following conclusion has been drawn based on the result obtained from the present study.

1. The concept of using Steel bracing is one of the advantages concept which has been used to strengthening of the structures

2. As the stiffness of the bracing framework of the structure increases then it also brings about increment of the buckling factor of the structure

3. Slenderness of the column play very vital role in buckling analysis of the Steel buildings from the result we can say that as the slenderness of the column increased the buckling factor will decrease i.e. Maximum load at which buckling failure occurs will decrease

4. The buckle factor obtained from the structure in soft soil is less when we compare in hard rock i.e. structural placed on the soft soil are likely to be more vulnerable to buckling failure compared to those placed in the hard rock.

\section{Reference}

[1] Adithya. M , Swathi rani K.S , Shruthi H K, Dr. Ramesh B.R, "Study On Effective Bracing Systems for High Rise Steel Structures", SSRG International Journal of Civil Engineering, ISSN: 2348 - 8352, volume 2, Issue 2, February 2015 , PP 19-22.

[2] BehroozFarshi, Farshad Koosheshon "Buckling analysis of structural steel frames with inelastic effects according to codes". Journal of construction of steel research, ASCE, 2009.

[3] Carlos Couto, Paulo Vila Real, Nuno Lopes, João Paulo Rodrigues on "Buckling analysis of braced and unbraced steel frames exposed to fire". Engineering Structures, ASCE, 2013.

[4] Chandrakant N.Thombare, Keshav K.Sangle, Vinod M. Mohitkar on "Nonlinear buckling analysis of 2-D cold-formed steel simple cross-aisle storage rack frames". Journal of Building Engineering, ASCE, 2016. 
[5] Christopher R. Urmson, John B. Mander on "Local Buckling Analysis of Longitudinal Reinforcing Bars". Journal of Structural Engineering, ASCE, 2009.

[6] Dhaval P.Advani, Dr. R.K. Gajjar.’'Investigation of Efficient Bracing System As Per IS 800:2007’. National Conference on Recent Trends in Engineering \& Technology.

[7] D. Camotim, C.Basaglia, N.Silvestre on "buckling analysis of thin-walled steel frames". Thin-Walled Structures 48 (2010) Pg. 726743 .

[8] Gazetas, G., (1991), "Formulas and Charts for Impedances of Surface and Embedded Foundations", Journal of Geotechnical Engineering, vol.117 (9), asce.

[9] John L. Dawe and Geoffrey L. Kulak, "Local Buckling Behaviour of Beam-Columns," Journal of Structural Engineering, ASCE, Vol. No. 112

[10] N.S. Trahair on "Buckling analysis design of steel frames". Journal of Constructional Steel Research, ASCE, 2009.

[11] Rekha Bhoi, L. G. Kalurkar on "Study of Buckling Behaviour of Beam and Column Subjected To Axial Loading for Various Rolled I Sections". International Journal of Innovative Research in Science, Engineering and Technology, 2014.

[12] KL Suresh P et.al. (2012), Influence of diagonal braces in CCmulti-storied frames under wind loads: A case Study. International Journal of Civil and Structural Engineering, 3(1), pp 214-226.

[13] Varghese, P.C. (2005), "Foundation Engineering” Prentice-Hall of India Private Limited, New Delhi, India.

[14] IS 800:2007, "General construction in steel - Code of Practice Bureau of Indian standards, New Delhi".

[15] IS: 875(Part-2)- 1987 “Code of Practice for Design Loads (Other than Earthquake) buildings and structures”, Part-2 Imposed loads, Bureau of Indian Standards, New Delhi.

[16] Viswanath K.G et.al. (2010), Seismic Analysis of Steel Braced Reinforced Concrete Frames, International Journal of Civil and Structural Engineering, 1(1), pp 114-116. 